\title{
Vigorous exercise in leisure time, coronary risk-factors, and resting electrocardiogram in middle-aged male civil servants
}

\author{
L. Epstein, ${ }^{1}$ G. J. Miller, ${ }^{2}$ F. W. Stitt, ${ }^{3}$ and J. N. Morris \\ From the Medical Research Council's Social Medicine Unit, Department of Community Health, London \\ School of Hygiene and Tropical Medicine, London
}

During 1968 to 1970, approximately 17000 middle-aged male executive grade civil service officers, all of them engaged in sedentary or very light work, recorded on a Monday morning their leisure time activities over the previous Friday and Saturday. In 1971 a sample of 509 of these men completed further questionnaires for medical, social, and smoking history; these men had a resting electrocardiogram, and height, weight, skinfold thickness, blood pressure, and plasma total cholesterol were measured. Vigorous exercise in leisure time had previously been reported by 125 (25\%) of the men, and these as a group had significantly fewer electrocardiographic abnormalities (changes compatible with myocardial ischaemia, ectopic beats, and sinus tachycardia) than the men not reporting vigorous exercise $(P<0 \cdot 02)$. This difference remained when all men with any history suggestive of cardiovascular disease were excluded from the analysis. Blood pressure, plasma total cholesterol, and smoking habits were examined with respect both to vigorous exercise and to the electrocardiogram, but the only relation found was that electrocardiographic abnormality increased with increasing blood pressure. Even among men with higher pressures, however, those reporting vigorous exercise had fezver electrocardiographic abnormalities than the others. The results provide further support for the association of habitual physical activity with coronary health.

Many studies have associated increased physical activity with a reduction in subsequent coronary morbidity and mortality (Morris et al., 1953; Fox and Haskell, 1968; Brunner et al., 1974; Paffenbarger and Hale, 1975), but few have examined its relation to electrocardiographic evidence of subclinical myocardial ischaemia. In Finland, Karvonen et al. (1961) found fewer abnormal electrocardiograms among lumberjacks than among men in other occupations. Keys et al. (1966) also reported less evidence of myocardial ischaemia in men with physically demanding work than in those in sedentary occupations. In Italy, railroad workers and men in rural districts, groups in which about 30 per cent

Received 28 October 1975.

${ }^{1}$ Present address: Department of Family and Community Health, Aba Khoushy Medical School and Rambam University Hospital, Haifa, Israel.

'Present address: MRC External Scientific Staff, Caribbean Epidemiology Centre, P.O. Box 164, Port of Spain, Trinidad. 'Present address: Syntex Laboratories, Inc., Palo Alto, California. and 65 per cent of men respectively were judged to be in heavy physical work, showed less electrocardiographic ischaemia than male clerks (Menotti et al., 1969). However, these authors were reluctant to conclude that there was a definite association between occupational physical activity and coronary health because they were unable to exclude the possibility that other factors relevant for coronary heart disease also differed between the groups contrasted.

In 1968 to 1970, Morris et al. (1973) recorded the leisure time activities of nearly 17000 male executive grade civil servants in the U.K. Men reporting vigorous exercise in leisure time had a smaller risk of subsequent coronary morbidity and mortality than their more sedentary colleagues. This study has now been extended in order to examine the relation between vigorous exercise, other recognized coronary risk factors, and electrocardiographic evidence of myocardial ischaemia within a group of men of similar occupational and socioeconomic 
status. The results provide further evidence for an inverse association between habitual physical activity and myocardial ischaemia.

\section{Subjects and methods}

The group from which the present men were drawn comprised 16882 male executive grade civil servants aged 40 to 65 years in six government departments in Britain. All were employed at sedentary or physically very light work. Between 1968 and 1970, each completed on an unannounced Monday morning a diary detailing activities during each five minutes of the previous Friday and Saturday (48 hours). No information was sought on activities during working hours. Questions were also asked about social, economic, and familial circumstances and on general medical history.

The method of analysis of the activity questionnaire has been given previously (Morris et al., 1973). Briefly, 'vigorous exercise' was defined as any activity likely to require a peak energy expenditure of $31.5 \mathrm{~kJ} \mathrm{~min}^{-1}(7.5$ $\mathrm{kcal} \mathrm{min}^{-1}$ ) and which, in the case of specified recreations, had lasted at least 5 minutes, and in the case of 'heavy work' had been performed either for more than 30 minutes continuously or for a total of one hour over the two-day period. Thus the men were divided into two exercise groups, those reporting vigorous exercise in leisure time and those not so reporting.

In 1971 a sample of 660 men was drawn from the original population and asked to collaborate in further studies. Of these, 509 agreed, giving a response rate of 77 per cent. Each completed a questionnaire for cardiovascular disease and answered the London School of Hygiene questionnaire for angina pectoris, prolonged chest pain, and intermittent claudication (Rose and Blackburn, 1968). Smoking habits were noted.

Height and weight were recorded and skinfold thickness was measured at three sites, subscapular, triceps, and supra-iliac, with Harpenden calipers. Casual blood pressure was recorded with the subject seated using a random zero sphygmomanometer (Hawksley). Two electrocardiograms were recorded at paper speeds of 2.5 and $5.0 \mathrm{~cm} \mathrm{~s}^{-1}$, respectively. Venous blood was withdrawn for plasma total cholesterol concentration measured by 'Autoanalyser' using a modified LiebermanBurchard method (Stitt et al., 1973).

All electrocardiograms were read independently by two observers according to Minnesota code criteria (Blackburn et al., 1960) and discrepancies were submitted to an arbitrator. Major $\mathrm{Q}$ wave changes (Minnesota code 1-1,2) were classified as definite myocardial ischaemia and lesser $Q$ wave changes (1-3), ST segment depression (4-1, 2, 3), $T$ wave inversion without evidence of left ventricular hypertrophy $(5-1,2)$, and complete bundle-branch block $(7-1,2)$ were taken as evidence for possible myocardial ischaemia. Subsequently, a third observer recorded the amplitude of the tallest $R$ wave in left praecordial leads (V5-V6), the duration of the PR interval in lead II, the occurrence of any premature beat, and the resting heart rate. All readings of the electrocardiograms and classification of activities were done independently and without any other information about the subjects. Frequency of electrocardiographic abnormality was then compared between the two exercise groups.

\section{Results}

Vigorous exercise as defined was reported by 125 of the 509 men $(24 \cdot 6 \%)$. Table 1 shows that as a group those reporting vigorous exercise were similar to those not reporting vigorous exercise with respect to age, height, weight, and skinfold thickness. Table 2 presents plasma total cholesterol and blood pressure according to exercise group; none of the differences achieved statistical significance though a smaller proportion of men reporting vigorous exercise had a plasma total cholesterol concentration above $6.4 \mathrm{mmol} 1^{-1}(249 \mathrm{mg} / 100 \mathrm{ml})$ compared with men not reporting vigorous exercise, and a slightly greater proportion of men in the vigorous exercise group had a systolic and diastolic blood pressure above $150 \mathrm{mmHg}(20 \mathrm{kPa})$ and $90 \mathrm{mmHg}(12.0 \mathrm{kPa})$ respectively (more detailed analysis of the higher ranges revealed nothing of interest). There were fewer non-smokers in the vigorous exercise group than in the no vigorous exercise group, and figures for current cigarette smoking were as low as 26 per cent and 32 per cent respectively (Table 3 ).

Table 4 gives the resting electrocardiographic findings. In all, 11 per cent of men reporting vigorous exercise had one or more noteworthy electrocardiographic abnormality compared with 22 per cent of men not reporting vigorous exercise

TABLE 1 Age and physique according to exercise group

\begin{tabular}{|c|c|c|c|c|}
\hline \multirow{9}{*}{$\begin{array}{l}\text { Mean age (yr) } \\
\% \text { aged } 40 \text { to } 49 \\
\% \text { aged } 50 \text { to } 59 \\
\% \text { aged } 60 \text { to } 65 \\
\text { Mean height }(\mathrm{m}) \\
\text { Mean weight }(\mathrm{kg}) \\
\text { Mean skinfold thickness } \\
\text { (mm) }\end{array}$} & \multirow{2}{*}{\multicolumn{2}{|c|}{$\begin{array}{l}\text { Reporting } \\
\text { vigorous exercise } \\
N=125\end{array}$}} & \multirow{2}{*}{\multicolumn{2}{|c|}{$\begin{array}{l}\text { Not reporting } \\
\text { vigorous exercise } \\
N=384\end{array}$}} \\
\hline & & & & \\
\hline & \multirow{7}{*}{$\begin{array}{c}50 \cdot 7 \\
41 \cdot 6 \\
48 \cdot 0 \\
10 \cdot 4 \\
1 \cdot 740 \\
74 \cdot 8\end{array}$} & \multirow{7}{*}{$\begin{array}{l}(5 \cdot 7) \\
(0 \cdot 068) \\
(9 \cdot 2)\end{array}$} & \multirow{4}{*}{$\begin{array}{r}50 \cdot 6 \\
37 \cdot 3 \\
54 \cdot 4 \\
8 \cdot 3\end{array}$} & \multirow[t]{4}{*}{$(5 \cdot 2)$} \\
\hline & & & & \\
\hline & & & & \\
\hline & & & & \\
\hline & & & \multirow{3}{*}{$\begin{array}{c}1.739 \\
73.9\end{array}$} & $(0.062)$ \\
\hline & & & & $(10.0)$ \\
\hline & & & & \\
\hline Triceps & $9 \cdot 3$ & $(3 \cdot 4)$ & $9 \cdot 6$ & $(3 \cdot 7)$ \\
\hline Subscapular & $17 \cdot 6$ & $(6 \cdot 2)$ & $17 \cdot 3$ & $(6.0)$ \\
\hline Suprailiac & $25 \cdot 1$ & $(7 \cdot 8)$ & $24 \cdot 9$ & $(7 \cdot 8)$ \\
\hline
\end{tabular}

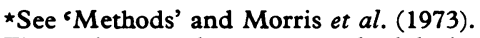

Figures in parentheses are standard deviations about the mean. None of these differences was statistically significant $(P>0.05)$. 
$(P<0.02)$. Prominent $Q$ waves $(1-1,2)$ were not found in any of the men reporting vigorous exercise while they occurred in 3 per cent of men not reporting vigorous exercise $(P<0.05)$. Similarly, the prevalence of possible myocardial ischaemia (except complete bundle-branch block); of ectopic beats; and of sinus tachycardia (Morris et al., 1966; Berkson et al., 1970), were all less in the vigorous exercise group than in the no vigorous exercise group.

Neither the $\mathbf{R}$ wave amplitude in left praecordial leads nor the duration of the PR interval in lead II appeared to be related to a history of vigorous exercise in leisure time. Thus the mean $R$ wave amplitude was $17.1 \mathrm{~mm}$ (SD 5.3 ) and $16.7 \mathrm{~mm}$ (SD 5.3) in the vigorous exercise group and no vigorous exercise group, respectively. An $\mathbf{R}$ wave amplitude of more than $26 \mathrm{~mm}$ occurred in $4(3.8 \%)$ men reporting vigorous exercise and 7 ( 1.8 per cent) men not reporting vigorous exercise $(P>0.05)$. The mean PR interval was $0.16 \mathrm{~s}$ (SD 0.02) in both groups and the mean heart rate was $75 \mathrm{~min}^{-1}$ (SD 15) and $76 \mathrm{~min}^{-1}$ (SD 15) for the vigorous exercise and no vigorous exercise group, respectively.

Table 5 relates the electrocardiographic findings to blood pressure, plasma total cholesterol, and smoking habits in the two exercise groups. Irrespective of exercise category, there was no trend to increasing electrocardiographic abnormality with increasing plasma total cholesterol. In both exercise groups the prevalence of electrocardiographic abnormality did increase with increasing blood pressure, but remained lower among men reporting vigorous exercise than in men not reporting vigorous exercise, even at hypertensive levels. Cigarette smoking was not associated with any excess of electrocardiographic abnormality in either exercise group.

In 118 men the questionnaire responses indicated either definite or possible cardiovascular disease (history of myocardial infarction, angina or prolonged chest pain, hypertension, cerebrovascular accident, intermittent claudication, exertional dyspnoea) or related disorder such as diabetes mellitus. They comprised 23 per cent of both exercise groups (29 of the 125 men reporting vigorous exercise and 89 of the 384 men not reporting vigorous exercise). Exclusion of these men from the analysis left the findings essentially unchanged; thus all types of electrocardiographic abnormality listed in Table 4 remained less prevalent among men reporting vigorous exercise. After age standardization on the remaining $391 \mathrm{men}, 9(9.4 \%)$ of 96 men reporting vigorous exercise had one or more electrocardio- graphic abnormalities, as compared with 55 (18.6\%) of the remaining 295 men not reporting vigorous exercise $(P<0.05)$. Ectopic beats were found in $1(1.8 \%)$ of the men reporting vigorous exercise and $15(5.5 \%)$ of the men not reporting vigorous exercise $(P>0.05)$.

Of the 118 men with clinical and/or 'questionnaire' evidence of cardiovascular disease, 65 gave a history of treatment for hypertension or diabetes mellitus or clinical coronary disease. Numbers are

TABLE 2 Plasma total cholesterol and casual arterial blood pressure according to exercise group

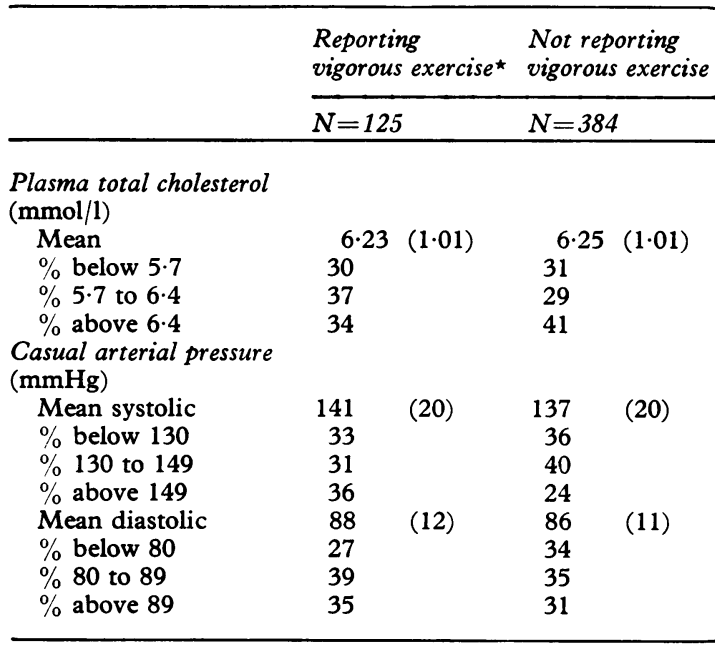

^See 'Methods' and Morris et al. (1973).

Figures in parentheses are standard deviations about the mean. None of the differences achieved statistical significance ( $\mathbf{P}>0.05)$.

Conversion factor from SI units to Traditional Units : cholesterol: $\mathrm{mmol} / \mathrm{l} \approx 38.7 \mathrm{mg} / 100 \mathrm{ml}$.

Conversion from Traditional Units to SI Units: $1 \mathrm{mmHg}$ $\approx 0.133 \mathrm{kPa}$.

TABLE 3 Smoking habits, according to exercise group

\begin{tabular}{lll}
\hline Smoking habits & $\begin{array}{l}\text { Reporting } \\
\text { vigorous exercise }\end{array}$ & $\begin{array}{l}\text { Not reporting } \\
\text { vigorous exercise }\end{array}$ \\
\cline { 2 - 3 } & $N=125$ & $N=384$ \\
\hline$\%$ Never smoked & 15 & 20 \\
$\%$ Pipe cigar only & 18 & 18 \\
$\%$ Ex-cigarette smokers & 41 & 31 \\
Current cigarette smokers & 26 & 32
\end{tabular}

None of these differences is statistically significant $(P>0.05)$. 
TABLE 4 Subjects with electrocardiographic changes, according to exercise group

\begin{tabular}{|c|c|c|c|}
\hline \multirow[t]{2}{*}{ Electrocardiographic reading } & \multirow[t]{2}{*}{ Minnesota code } & $\begin{array}{l}\text { Reporting } \\
\text { vigorous exercise* }\end{array}$ & $\begin{array}{l}\text { Not reporting } \\
\text { vigorous exercise }\end{array}$ \\
\hline & & 125 men & 384 men \\
\hline $\begin{array}{l}\text { Definite and possible myocardial ischaemia } \\
\text { One or more ectopic beats } I \\
\text { Sinus tachycardia } \\
\text { Men with any of the above observations }\end{array}$ & $8-7$ & $\begin{array}{l}6(4 \cdot 8) \\
3(2 \cdot 2) \\
7(5 \cdot 6)\end{array}$ & $\begin{array}{l}40(10 \cdot 4) \dagger \\
27(7 \cdot 1) \dagger \\
34(8 \cdot 7) \quad 83(22 \cdot 1) \ddagger\end{array}$ \\
\hline $\begin{array}{l}\text { Definite ischaemia } \\
\quad \text { Major } \mathrm{Q} / \mathrm{QS} \text { patterns }\end{array}$ & $1-1,2$ & 0 & 11 \\
\hline $\begin{array}{l}\text { Possible ischaemia } \\
\text { Minor Q/QS patterns } \\
\text { ST segment depression } \\
\text { T wave inversion } \\
\text { Complete bundle-branch block }\end{array}$ & $\begin{array}{l}1-3 \\
4-1,2,3 \\
5-1,2 \\
7-1,2\end{array}$ & $\begin{array}{l}1 \\
3 \\
0 \\
2\end{array}$ & $\begin{array}{r}5 \\
23 \\
9 \\
5\end{array}$ \\
\hline Supraventricular ectopic beats & & 1 & 10 \\
\hline Ventricular ectopic beats & & 2 & 17 \\
\hline Ectopic beats comprising 10 per cent or more of recorded cycles & $8-1$ & 1 & 14 \\
\hline
\end{tabular}

*Vigorous exercise as defined in 'Methods' and Morris et al. (1973).

$\uparrow P<0.05 ; \ddagger P<0.02$. When numbers are small, the significance of differences between groups was tested by the method of Gart (1962).

TWithin age range 55 to 64 years: $2(4.8 \%)$ of 42 men reporting vigorous exercise; $11(10.3 \%)$ of 107 men not reporting vigorous exercise.

Figures in parentheses are age-standordized rates. There were, in all, 6 instances of definite or possible ischaemic changes in 6 men who reported vigorous exercise, and 53 instances in 40 men who did not report vigorous exercise.

TABLE 5 Prevalence of electrocardiographic abnormalities in relation to plasma total cholesterol, casual blood pressure, smoking habits, and vigorous exercise in leisure time

\begin{tabular}{|c|c|c|c|c|}
\hline & \multicolumn{2}{|c|}{ Men reporting vigorous exercise } & \multicolumn{2}{|c|}{ Men not reporting vigorous exercise } \\
\hline & Total No. & $\%$ with ECG abnormalities & Total No. & $\%$ with ECG abnormalities \\
\hline $\begin{array}{l}\text { Plasma total cholesterol }(\mathrm{mmol} / \mathrm{l}) \\
\text { below } 5 \cdot 7 \\
5 \cdot 7-6 \cdot 4 \\
\text { above } 6 \cdot 4\end{array}$ & $\begin{array}{l}37 \\
46 \\
42\end{array}$ & $\begin{array}{r}13 \cdot 5 \\
13 \cdot 0 \\
7 \cdot 1\end{array}$ & $\begin{array}{l}117 \\
107 \\
160\end{array}$ & $\begin{array}{l}23 \cdot 9 \\
16 \cdot 8 \\
23 \cdot 1\end{array}$ \\
\hline $\begin{array}{l}\text { Systolic blood pressure }(\mathrm{mmHg})+ \\
\text { below } 130 \\
130-149 \\
\text { above } 149\end{array}$ & $\begin{array}{l}41 \\
39 \\
44\end{array}$ & $\begin{array}{r}4 \cdot 9 \\
7 \cdot 7 \\
20 \cdot 5\end{array}$ & $\begin{array}{r}137 \\
154 \\
91\end{array}$ & $\begin{array}{l}13 \cdot 9 \\
20 \cdot 8 \\
34 \cdot 1\end{array}$ \\
\hline $\begin{array}{l}\text { Diastolic blood pressure }(\mathrm{mmHg}) \dagger \\
\text { below } 80 \\
80-89 \\
\text { above } 89\end{array}$ & $\begin{array}{l}34 \\
44 \\
46\end{array}$ & $\begin{array}{r}8 \cdot 8 \\
6 \cdot 8 \\
17 \cdot 4\end{array}$ & $\begin{array}{l}130 \\
134 \\
118\end{array}$ & $\begin{array}{l}15 \cdot 4 \\
21 \cdot 6 \\
28 \cdot 0\end{array}$ \\
\hline $\begin{array}{l}\text { Smoking habits } \\
\text { Never smoked } \\
\text { Pipe/cigar only } \\
\text { Ex-smokers } ¥ \\
\text { Current smokers } ¥\end{array}$ & $\begin{array}{l}18 \\
23 \\
52 \\
32\end{array}$ & $\begin{array}{r}22 \cdot 2 \\
13 \cdot 0 \\
5 \cdot 8 \\
12 \cdot 5\end{array}$ & $\begin{array}{r}76 \\
68 \\
117 \\
123\end{array}$ & $\begin{array}{l}25 \cdot 0 \\
28 \cdot 0 \\
15 \cdot 4 \\
22 \cdot 0\end{array}$ \\
\hline
\end{tabular}

$\star$ As in Table 4.

†Not recorded in one subject reporting vigorous exercise and two subjects not reporting vigorous exercise.

¥Cigarettes with or without other types of tobacco smoking.

Conversion from SI Units to Traditional Units: Cholesterol: $1 \mathrm{mmol} / 1 \approx 38.6 \mathrm{mg} / 100 \mathrm{ml} .1 \mathrm{mmHg} \approx 0 \cdot 133 \mathrm{kPa}$. 
now very small, but in this group of 65 men, 3 $(15.8 \%)$ of the 19 reporting vigorous exercise had one or more changes of definite or possible ischaemia compared with $17(37.0 \%)$ of the 46 not reporting vigorous exercise. The figures for ectopic beats were $1(5.3 \%)$ and $7(15 \cdot 2 \%)$ respectively. Of the 53 men with 'questionnaire' evidence alone, 10 men not reporting vigorous exercise had electrocardiographic abnormalities, compared with none of those reporting vigorous exercise.

\section{Discussion}

In any epidemiological study which compares coronary morbidity and mortality in groups with differing habitual physical activity, due allowance must be made for the possible effects of other socioeconomic factors which might differ between the groups (Morris, 1975). In order to minimize these unwanted effects, the present study was confined to middle-aged men who were all government employees with uniform occupations and socioeconomic status ('white collar', and within a narrow band of the middle class). The two exercise groups were remarkably alike over a wide range of social indices (Morris et al., 1973), and the similarity of skinfold thickness and plasma total chlesterol in the two groups may be some indication of the success of this technique. Keys et al. (1966) found that skinfold thickness, blood pressure, and serum cholesterol levels were inversely related to occupational physical activity, but that these apparent effects of physical activity were much reduced when some allowance was made for associated differences in socioeconomic status. The differences in the electrocardiogram in the present study between the two exercise groups are thought to be unlikely to be a consequence of other socioeconomic variables related to the pattern of physical activity.

An alternative interpretation of these data could be that the men with electrocardiographic abnormality tended to avoid leisure activity for health reasons related to ischaemic heart disease. Both Menotti et al. (1969) and Paffenbarger and Hale (1975) concluded from their own extensive data that this type of behavioural change must be very uncommon before the onset of clinical disease. In the present study, no excess of subjects with either symptoms or a clinical history of possible cardiovascular disease was, in fact, found among those not reporting vigorous exercise. And the findings remained essentially unchanged when these men were excluded from the analysis. There seemed, therefore, little likelihood that men with electrocardiographic changes had, at least one year before the electrocardiographic examination in 1971 (the activity questionnaire had been completed at some time between 1968 and 1970), changed their pattern of leisure activity for reasons related to coronary disease. More probably, the findings indicated that physical activity in some way promoted coronary health. Thus, they confirm the earlier finding (Morris et al., 1973) of a reduced subsequent incidence of clinical coronary heart disease in the vigorous exercise group as compared with the no vigorous exercise group.

An increase in ectopic beats in physically inactive men has not apparently been reported previously. Karvonen et al. (1961) found similar rates of arrhythmia in lumberjacks and in men in less physically demanding occupations. While ectopic beats have many causes, impairment of the coronary circulation with inadequate oxygen delivery might predispose to arrhythmias (Watanabe and Dreifus, 1968; Samuelsson, 1973). Since men not reporting vigorous exercise also had more electrocardiographic changes compatible with myocardial ischaemia, their excess of ectopic beats could have been a result of ischaemic heart disease.

The protective action of vigorous exercise did not appear to be related to plasma total cholesterol, casual blood pressure, adiposity, or smoking habits. In other studies examining the relation between plasma total cholesterol and habitual physical activity, the results have been inconsistent (Keys et al., 1966; Menotti et al., 1969; Grimby et al., 1971; Taylor, Buskirk, and Remington, 1973; Brunner et al., 1974). This does not exclude the possibility that consistent group differences existed in the distribution of total cholesterol between the several plasma lipoproteins. Increased physical activity increases high density lipoprotein cholesterol while reducing low density lipoprotein cholesterol (Lopez-S et al., 1974; Wood et al., 1974), and on this account might improve coronary health (Miller and Miller, 1975; Lewis et al., 1974; Gulbrandsen, Rhodes, and Kagan, 1974; Morris, 1975) even when plasma total cholesterol shows little change.

The absence of any increase in resting electrocardiographic abnormality with either cigarette smoking or increased plasma cholesterol is in agreement with earlier studies. Neither Epstein et al. (1965) nor Keys et al. (1966) showed any significant relation between these factors and electrocardiographic abnormalities when these included ST segment depression and $T$ wave inversion. Indeed, as in the present study, Epstein et al. (1965) found fewer changes in smokers than in non-smokers. Since both cigarette smoking and a raised plasma 
total cholesterol are associated with an increased coronary mortality (Simborg, 1969), the meaning of these findings is unclear. Some men who were at risk for these reasons might have been excluded from the study population by earlier death. Cigarette smoking may be more strongly associated with the acute coronary event than the development of atherosclerosis (Gordon, Kannel, and McGee, 1974). The observations on plasma total cholesterol might be clarified when electrocardiographic changes are examined with respect to the plasma lipoproteins rather than plasma total cholesterol, and during exercise rather than at rest. Thus both Motta et al. (1974) and Carlson, Ekelund, and Olsson (1975) found that ischaemic ST segment depression during exercise occurred more frequently in subjects with hyperlipidaemia than in normal subjects. Many studies, on the other hand, have confirmed the association between electrocardiographic abnormality and blood pressure (Epstein et al., 1965; Keys et al., 1966; Miall et al., 1972), and it is interesting (Table 5) to note the protective effect of vigorous exercise in the presence of a raised blood pressure (Morris, 1975).

While numbers are very small, the protective effect of exercise in hypertension appeared to explain much of the reduction in frequency of electrocardiographic abnormalities in those men reporting vigorous exercise within the group of 118 men who had clinical or questionnaire evidence of cardiovascular disease. There was also some evidence that effort symptoms (chest pain, dyspnoea, claudication) were less likely to be associated with electrocardiographic abnormality in men reporting vigorous exercise than in those who did not take vigorous exercise.

Heavy occupational and athletic activities are associated with an increased $\mathbf{R}$ wave amplitude, sinus bradycardia, and a prolonged $P R$ interval (Karvonen et al., 1961; Keys et al., 1966; Van Ganse et al., 1970). None of these changes was evident among men reporting vigorous exercise, and this observation suggests that the patterns of recreational activity which promote coronary health are not necessarily as vigorous as those associated with athleticism.

Further studies of this nature will be improved by the application of more sensitive and more specific methods of measurement of myocardial ischaemia and habitual physical activity. The study of Carlson et al. (1975), for example, illustrates the usefulness of exercise electrocardiography in epidemiology. Appropriate assessment of 'physical fitness', using the cardiovascular response to test exercise (Cotes, 1972), may prove a more useful even though indirect measure of habitual physical activity for survey purposes than questionnaire methods (Gyntelberg, 1974). Examination of the relations between these measurements within each of a range of socioeconomic groups may take us a step further in our understanding of the association between the pattern of habitual physical activity and coronary health.

We are grateful again to our friends in the Civil Service, to colleagues for use of data, to Professor G. A. Rose and colleagues for reading the electrocardiograms, and to Mr. J. Woods for computer assistance.

\section{References}

Berkson, D. M., Stamler, J., Lindberg, H. A., Miller, W. A., Stevens, E. L., Soyugenc, R., Tokich, T. J., and Stamler, R. (1970). Heart rate: an important risk factor for coronary mortality. Ten year experience of the Peoples Gas Co. In Atherosclerosis: Proceedings of the Second International Symposium, p. 382 . Ed. by R. J. Jones. Springer, Berlin.

Blackburn, H., Keys, A., Simonson, E., Rautaharju, P., and Punsar, S. (1960). The electrocardiogram in population studies. A classification system. Circulation, 21, 1160.

Brunner, D., Manelis, G., Modan, M., and Levin, S. (1974). Physical activity at work and the incidence of myocardial infarction, angina pectoris and death due to ischemic heart disease. An epidemiological study in Israeli collective settlements (kibbutzim). Fournal of Chronic Diseases, 27, 217.

Carlson, L. A., Ekelund, L. G., and Olsson, A. G. (1975). Frequency of ischaemic exercise ECG changes in symptomfree men with various forms of primary hyperlipaemia. Lancet, $2,1$.

Cotes, J. E. (1972). Response to progressive exercise, a threeindex test. British fournal of Diseases of the Chest, 66, 169.

Epstein, F. H., Ostrander, L. D., Johnson, B. C., Payne, M. W., Hayner, N. S., Keller, J. B., and Francis, T. (1965). Epidemiological studies of cardiovascular disease in a total community-Tecumseh, Michigan. Annals of Internal Medicine, 62, 1170.

Fox, S. M., and Haskell, W. L. (1968). Physical activity and the prevention of coronary heart disease. Bulletin of the New York Academy of Medicine, 44, 950.

Gart, J. J. (1962). Approximate confidence limits for the relative risk. Fournal of the Royal Statistical Society, Series B, 24, 454.

Gordon, T., Kannel, W. B., and McGee, D. (1974). Death and coronary attacks in men after giving up cigarette smoking. Lancet, 2, 1345.

Grimby, G., Wilhelmsen, L., Bjorntorp, P., Saltin, B., and Tibblin, G. (1971). Habitual physical activity; aerobic power and blood lipids. In Muscle Metabolism During Exercise, p. 469. Ed. by B. Pernow and B. Saltin. Plenum Press, New York.

Gulbrandsen, C. L., Rhoads, G. G., and Kagan, A. (1974). Cholesterol fractions and coronary heart disease in Hawaii Japanese men. Circulation, 49, Suppl. III, 100.

Gyntelberg, F. (1974). Physical fitness and coronary heart disease in Copenhagen men aged 40-59. III. (Factor relating to working capacity.) Danish Medical Bulletin, 21, 49.

Karvonen, M. J., Rautaharju, P. M., Orma, E., Punsar, S., and Takkunen, J. (1961). Heart disease and employment. Cardiovascular studies on lumberjacks. Fournal of Occupational Medicine, 3, 49. 
Keys, A., Aravanis, C., Blackburn, H. W., van Buchem, F. S. P., Buzina, R., Djordevic, B. S., Dontas, A. S., Fidanza, F., Karvonen, M. J., Kimura, N., Lekos, D., Monti, M., Puddu, V., and Taylor, H. L. (1966). Epidemiological studies related to coronary heart disease; characteristics of men aged 40-59 in seven countries. Acta Medica Scandinavica, Suppl. 460.

Lewis, B., Chait, A., Oakley, C. M. O., Wooton, I. D. P., Krikler, D. M., Onitiri, A., Sigurdsson, G., and February, A. (1974). Serum lipoprotein abnormalities in patients with ischaemic heart disease; comparison with a control population. British Medical fournal, 3, 489.

Lopez-S, A., Vial, R., Balart, L., and Arroyave, G. (1974). Effect of exercise and physical fitness on serum lipids and lipoproteins. Atherosclerosis, 20, 1.

Menotti, A., Puddu, V., Monti, M., and Fidanza, F. (1969). Habitual physical activity and myocardial infarction. Cardiologia, 54, 119.

Miall, W. E., Del Campo, E., Fodor, J., Nava Rhode, J. R., Ruiz, L., Standard, K. L., and Swan, A. V. (1972). Longitudinal study of heart disease in Jamaican rural population. 1. Prevalence, with special references to ECG findings. Bulletin of the World Health Organization, 46, 429.

Miller, G. J., and Miller, N. E. (1975). Plasma-high-densitylipoprotein concentration and development of ischaemic heart-disease. Lancet, 1, 16.

Morris, J. N. (1975). Uses of Epidemiology. Churchill Livingstone, Edinburgh.

Morris, J. N., Chave, S. P. W., Adam, C., Sirey, C., Epstein, L., and Sheehan, D. J. (1973). Vigorous exercise in leisuretime and the incidence of coronary heart-disease. Lancet, $1,333$.

Morris, J. N., Heady, J. A., Raffle, P. A. B., Roberts, C. G., and Parks, J. W. (1953). Coronary heart-disease and physical activity of work. Lancet, 2, 1053 and 1111.

Morris, J. N., Kagan, A., Pattison, D. C., Gardner, M. J., and Raffle, P. A. B. (1966). Incidence and prediction of ischaemic heart-disease in London busmen. Lancet, 2, 553.
Motta, J. A., Haskell, W., Stern, M., and Bailey, J. (1974). Submaximal exercise testing in a random and high lipid samples from three Northern California communities. Circulation, 49, Suppl. III, 115.

Paffenbarger, R. S., and Hale, W. E. (1975). Work activity and coronary heart mortality. New England fournal of Medicine, 292, 545.

Rose, G. A., and Blackburn, H. (1968). Cardiovascular Survey Methods. World Health Organization, Geneva.

Samuelsson, R. (1973). Effects of severe systemic hypoxia on myocardial excitation. Acta Physiologica Scandinavica, 88, 267.

Simborg, D. W. (1969). The status of risk factors and coronary heart disease. Fournal of Chronic Diseases, 22, 515.

Stitt, F. W., Clayton, D. G., Crawford, M. D., and Morris, J. N. (1973). Clinical and biochemical indicators of cardiovascular disease among men living in hard and soft water areas. Lancet, 1, 122.

Taylor, H. L., Buskirk, E. R., and Remington, R. D. (1973). Exercise in controlled trials of the prevention of coronary heart disease. Federation Proceedings, 32, 1623.

Van Ganse, W., Versee, L., Eylenbosch, W., and Vuylsteek, K. (1970). The electrocardiogram of athletes: comparison with untrained subjects. British Heart fournal, 32, 160.

Wood, P. D., Klein, H., Lewis, S., and Haskell, W. L. (1974). Plasma lipoprotein concentrations in middle-aged male runners. Circulation, 49, Suppl. III, 115.

Watanabe, Y., and Dreifus, L. S. (1968). Newer concepts in the genesis of cardiac arrythmias. American Heart fournal, 76, 114.

Requests for reprints to Professor J. N. Morris, Department of Community Health, London School of Hygiene and Tropical Medicine, Keppel Street, London W.C.1. 